Keywords: Homeless, Young people, Outcome, Mental health, Services, HoNOS.

\title{
Short-term outcome of young homeless people in contact with a designated mental health service
}

\author{
Helen Taylor* \\ Maria Stuttaford ${ }^{\star \star}$ \\ Panos Vostanis ${ }^{\star \star *}$ \\ * Research Associate, University of Leices- \\ ter, UK \\ ** Lecturer in Human Geography, University \\ of St Andrews, UK \\ *** Professor of Child and Adolescent Psy- \\ chiatry, University of Leicester, Greenwood \\ Institute of Child Health
}

UNITED KINGDOM

\begin{abstract}
Background and Objectives: Young homeless people have high rates of psychiatric disorders and related complex needs. However, they often find it difficult to access mainstream mental health services. The aim of this study was to establish the shortterm clinical outcome of young homeless people in contact with a designated mental health service, and whether this is predicted by variables in young people's profiles.

Methods: A designated mental health service was provided across five areas covering 18 shelters for young homeless people aged 16-25 years. Data on 150 consecutively referred young people, included the Health of the Nation Outcome Scales (HoNOS), a risk assessment, and a service checklist at referral and final service contact.

Results: Young people reported a range of previous adversities and service contacts, and high HoNOS and risk scores. There was significant improvement on most HoNOS items for those who attended more than one session, but only one risk behaviour (selfharm) significantly decreased. Previous experience of mental health problems and agreed completion of treatment predicted better clinical outcome.

Conclusions: Despite their multiple and complex mental health needs, at least a proportion of young homeless people, can engage and benefit from their contact with a designated mental health service. The HoNOS could be a useful clinical tool for similar community teams.
\end{abstract}

Received 30 April 2007

Revised 23 September 2007

Accepted 7 November 2007 


\section{Introduction}

Young homeless people are on the increase worldwide, because of lower incomes and unemployment, less affordable housing, and restrictions on social care benefits. Some figures quote as many as 100 million homeless adolescents worldwide, 40 million of whom are in Latin America, 30 million in Asia and 10 million in Africa ${ }^{1}$. In the US, about 750,000 school-age children and adolescents are homeless in the course of a year, with this figure doubling when old teenagers and young adults are included ${ }^{2}$. Young homeless people in the UK have been consistently identified as demonstrating a range of complex needs, with high prevalence rates of a number of disorders such as depression, post-traumatic stress disorders, psychosis and substance misuse ${ }^{3}$. Psychiatric disorders have been found to be significantly associated with previous adverse experiences of family breakdown, abuse, residential care, poor educational attainment, and instability of accommodation $^{4-5}$. These are likely to persist in the absence of treatment ${ }^{6-7}$. Despite the severity and high prevalence of psychiatric disorders, young homeless people cannot easily access mental health services ${ }^{3,8}$. Reasons include mobility between service boundaries; falling between adolescent and adult services; perceived stigma; not fulfilling referral criteria for severe mental illness; and lack of co-ordination between mental health, social, housing and non-statutory services ${ }^{1}$.

Although some mental health service models have been reported and evaluated for adult homeless people ${ }^{9}$, there have been few mental health service initiatives for young homeless people, with described services often developed by non-statutory agencies ${ }^{10}$. In a UK survey of homeless shelters for young people, only $27 \%$ reported that they had adequate supports, arrangements or resources to meet young people's mental health needs ${ }^{11}$. A variety of models were adopted such as use of family practices, outreach work, referral to external mental health services, or in-house provision, but these were developed ad hoc, usually as a result of local personal initiatives.

Difficulties in establishing such service outcomes are compounded by the multiplicity of young people's needs, their developmental and chronological age in the transition between adolescence and adulthood, their high service turnover, and their potential loss to service follow-up. Consequently, it may be more difficult for mental health practitioners working with this vulnerable group to systematically collect comparable outcome data than professionals working in generic mental health services.

The Health of the Nation Outcome Scales (HoNOS) constitutes such an example of a widely used service measure of psychosocial functioning. The HoNOS were developed in the UK by the Royal College of Psychiatrists to form a brief and simple outcome measure to record a patient's progress throughout routine clinical practice within a range of mental health service settings ${ }^{12-13}$, and have since been adopted in different countries, predominantly Australia ${ }^{14}$. Following early trials, a number of studies have examined the use of the HoNOS in a variety of in-patient and out-patient adult mental health services ${ }^{15}$, including a psychotherapy service ${ }^{16}$. Despite some criticisms of its psychometric properties ${ }^{17}$, other researchers however have found HoNOS to be a sensitive measure or predictor of change ${ }^{18}$. Therefore, the original recommendation that HoNOS should be used as a routine measure in adult 
mental health care has received support from several reviewers ${ }^{19-21}$.

Although there is a growing body of evidence on young homeless people's mental health needs, there is limited knowledge on their service outcomes and potential benefits from services. The primary aim was, therefore, to establish the short-term clinical outcome of young homeless people in contact with a designated mental health service provided at homeless shelters in different UK regions. A secondary aim was to establish factors in the young people's profile and their contacts with the service, that were associated with improved clinical outcome.

\section{Method}

\section{Setting and sample}

A network of 132 homeless shelters (Foyers) across the UK provide accommodation and preparation for independence for young homeless people. These were defined as 'homeless' if statutorily accepted by local authorities (housing departments), and were accommodated by a shelter prior to rehousing and re-integration in the community. Because of their extent of unmet need, a mental health service was set up on the interface between the shelters and the local mental health services. At the first stage, it provided input to 18 shelters in five UK regions through five mental health professionals. A total of 150 young people were referred to the mental health professionals during the first year, and constituted the sample of this study. Their mean age was 19.0 years (16-29); $53.3 \%$ were male, and $46.7 \%$ female. Most $(86.6 \%)$ of the young people were White British, $4.0 \%$ of mixed race, $1.3 \%$ Black Caribbean, $1.3 \%$ Black
African, 2.0\% Black British, and 4.7\% from other ethnic groups.

\section{Young people's profile, risk assessment and service contacts}

A service checklist was completed for each young person at the time of referral, and at completion of service contact. This included structured information on their history, previous service contacts, risk behaviours, and contacts with the service. Over half of the young people had been referred by homeless shelters staff (62.4\%), a further $28.9 \%$ were self-referred, and the remaining $8.9 \%$ were referred by external agencies. Homeless shelter staff had social care background and training. They made young people aware of the mental health service on admission and at regular intervals. If either the staff detected concern about a young person, or a young person approached them with mental health concerns, a referral was initiated to the service, always with the young person's consent.

Their psychosocial profile showed a range of longstanding adverse experiences. Frequencies are presented below, because of missing data in some variables ranging between 1-10 cases of the total 150. About three-quarters $(77.5 \%)$ had previously taken drugs, $66.7 \%$ had considered suicide, $54.6 \%$ had been bullied, $48.6 \%$ had self-harmed, $43.3 \%$ had been physically abused as a child, $30.9 \%$ had attempted suicide, $28.8 \%$ had taken an overdose, $27.3 \%$ had slept on the streets, $25.8 \%$ had been physically abused as an adult, $20.8 \%$ had been sexually abused as a child, $14.8 \%$ had been sexually assaulted as an adult, and $12.8 \%$ had previously been in care. Additionally, $69.6 \%$ of 
young people reported that they had previously experienced mental health problems.

At the time of referral to the mental health service, a clinical risk assessment was completed on each young person. Current risk was assessed by the mental health professionals in a number of areas, which are fairly standard in adult mental health services. Risk was classified as 'low', 'medium' or 'high', with an allocated respective score of 1-2-3. When 'medium' and 'high' scores were grouped as definite risk, a large number of young people was considered as currently being a risk to themselves through either alcohol abuse $(50.0 \%)$, reckless, impulsive behaviour (45.5\%), self-harm (45.1\%), drug abuse $(40.1 \%)$, and lack of self-care $(34.9 \%)$. A lower but still substantial proportion of young people were assessed as being a current risk to other people through either threatening behaviour (35.0\%) or the potential to cause physical harm $(24.5 \%)$. Furthermore, young people were found to be at current risk of harm by other people, from either physical $(23.6 \%)$ or sexual abuse $(5.6 \%)$.

\section{The Health of the Nation Outcome Scales (HoNOS)}

The Health of the Nation Outcome Scales $\left(\mathrm{HoNOS}^{12}\right)$ assess a range of mental health and social functioning needs and comprise of 12 subscales (Table I). Each item is rated on a five-point severity scale. The HoNOS has been found reliable when adequate attention is given to training of clinicians and maintenance of quality control ${ }^{13}$. Following the instrument guidelines ${ }^{14}$, the mental health professionals received group training from to encourage the accurate collection of data. This included structure and scoring, key principles of conducting ratings, and detailed group discussion on each scale item. In line with these training recommendations, the mental health professionals then practiced individually, rating clinical case vignettes, and by group discussion with the researcher, until consensus was reached. Two clinical vignettes were mailed to all mental health professionals every three months, during the year long rating period, to sustain reliability. HoNOS were completed following their first contact with the young person, and at the end of their clinical contact.

\section{Statistical analysis}

Frequencies and descriptive statistics were initially presented. Due to the abnormal distribution of scores within the data set, non-parametric tests were used to further explore the relationships between variables. Mann-Whitney $U$ tests were used to investigate whether there were any significant demographic differences between the sub-groups of young people who either had contact with the mental health service once, or who continued to engage with the service. Wilcoxon signed ranks tests were used to investigate the differences between preand post-intervention HoNOS sub-scale and total scores, and between of pre- and postintervention risk assessment scores. A new variable was created by subtracting the postintervention HoNOS total score from the pre-intervention HoNOS total score to produce a change score for each young person. Mann-Whitney $U$ tests were used to compare the differences between change scores across subgroups of young service users as defined by dichotomous demographic, history, risk, and service variables. The association between a further four continuous demographic, assessment and interventional 
variables and HoNOS total change scores was further investigated through the use of Spearman's Rank Correlation Coefficient.

\section{Results}

\section{HoNOS scores at first assess- ment}

The mean total HoNOS score for this sample was 9.05 (s.d. $=5.37$, range 0-27, out of maximum 48), which was similar to scores reported within other clinical samples such as clients of community mental health teams $\left(\right.$ Salvi et al. ${ }^{21}$ : mean score $\left.=9.7\right)$ and psy- chotherapy services (Audin et al. ${ }^{16}$ : mean score $=8.9$ ). Eighty young people were identified as experiencing 'other mental and behavioural problems' on the HoNOS scale item $8(n=149)$. In 79 of these cases, the type of other mental or behavioural problem was specified in regard to sleep (25), anxiety (23), eating (12), mental strain/tension (9), and obsessive-compulsive thoughts and behaviours (6). Table I displays the frequencies of HoNOS subscales scores (between 1 and 4) at the first assessment. HoNOS scores of 2-4 have been established as of potential clinical importance, by indicating either a clinical or social problem that signifies the consideration of further intervention ${ }^{12}$.

Table I

Frequencies of HoNOS subscales scores at first assessment $(n=149)$.

\begin{tabular}{|c|c|c|c|c|c|c|}
\hline HoNOS subscale & 0 & 1 & 2 & 3 & 4 & $\begin{array}{c}2+3+4 \\
(\mathrm{~N})\end{array}$ \\
\hline $\begin{array}{l}\text { 1: Overactive, aggressive, disruptive or agitated } \\
\text { behaviour }\end{array}$ & 51.8 & 26.4 & 14.6 & 9.5 & 7 & $24.8 \%(\mathrm{n}=37)$ \\
\hline 2: Non-accidental self-injury & 54.3 & 19.5 & 16.1 & 5.4 & 4.7 & $26.2 \%(\mathrm{n}=39)$ \\
\hline 3: Problem drinking or drug-taking & 44.3 & 27.5 & 23.5 & 3.4 & 1.3 & $28.2 \%(\mathrm{n}=42)$ \\
\hline 4: Cognitive problems & 75.3 & 16.7 & 5.3 & 2.7 & .0 & $8.0 \%(\mathrm{n}=12)$ \\
\hline 5: Physical illness or disability problems & 75.9 & 13.4 & 6.7 & 2.7 & 1.3 & $10.7 \%(\mathrm{n}=16)$ \\
\hline 6: Problems with hallucinations or delusions & 87.3 & 2.0 & 6.0 & 4.7 & .0 & $10.7 \%(\mathrm{n}=16)$ \\
\hline 7: Problems with depressed mood & 18.7 & 24.2 & 38.3 & 15.4 & 3.4 & $57.1 \%(\mathrm{n}=85)$ \\
\hline 8: Other mental and behavioural problems & 46.3 & 12.1 & 27.5 & 12.1 & 2.0 & $41.6 \%(n=62)$ \\
\hline 9: Problems with relationships & 22.8 & 34.2 & 30.9 & 11.4 & .7 & $43.0 \%(n=64)$ \\
\hline 10: Problems with activities of daily living & 55.4 & 26.0 & 15.3 & 3.3 & .0 & $18.6 \%(\mathrm{n}=28)$ \\
\hline 11: Problems with living conditions & 71.1 & 16.8 & 8.1 & .0 & 4.0 & $12.1 \%(\mathrm{n}=18)$ \\
\hline 12: Problems with occupation and activities & 72.4 & 21.5 & 5.4 & .7 & .0 & $6.1 \%(\mathrm{n}=9)$ \\
\hline
\end{tabular}

HoNOS subscales scoring code:

0 : No problem

1: Minor problem requiring no action

2: Mild problem but definitely present

3: Moderately severe problem

4: Severe to very severe problem

\section{Service contacts}

Seventy-six of the young people referred to the mental health service did not have any further contact after the initial assessment
( $n=150)$. Reasons for early termination of contact did not fall into exclusive categories, and included: the young person choosing not to continue contact $(n=23)$; 
need not being deemed sufficient to warrant further intervention $(n=17)$; being in contact with another appropriate service $(\mathrm{n}=11)$; inappropriate referral $(\mathrm{n}=7)$; and leaving the homeless shelter $(n=6)$. No patient required involuntary treatment during the course of the study.

For the remaining young people $(n=74)$, the number of attended sessions varied between 2-19, with a mean number of 5.5 sessions $(n=69)$. Within these sessions, a variety of skills and interventions were used by the mental health professionals, including counselling skills, cognitive-behavioural therapy, substance use interventions, and psycho-education. Less than half of the young people who continued to engage with the service $(\mathrm{n}=30)$ had a 'planned' final contact with their mental health professional. The mental health professionals were found to be 'satisfied' with the number of sessions held with only just over half of their clients $(n=40)$. Mann-Whitney $U$ tests revealed no significant differences between the two groups of young people who either $\operatorname{did}(n=74)$, or did not $(n=76)$ engage with the mental health service after their first assessment on demographic variables, total HoNOS scores $(U=2438.00, Z=-1.41$, $\mathrm{p}=\geq 0.05$, two-tailed), or individual HoNOS items at assessment.

\section{Comparison of pre- and post- intervention HoNOS scores}

Follow-up HoNOS scores were completed for 68 out of the 74 young people who had attended more than one session. The mean assessment scores are compared further to the mean discharge scores for each HoNOS subscale within Table II (Wilcoxon signed ranks test). Change was found to be statistically significant between assessment and discharge on most HoNOS sub-scale items, except for physical illness or disability problems, and living conditions. The decrease in total HoNOS scores between assessment and discharge was also statistically significant $(Z=5.67, \mathrm{p}<0.001$, twotailed).

Table II

Comparison between HoNOS mean assessment and discharge scores $(n=68)$.

\begin{tabular}{|c|c|c|c|}
\hline HoNOS scale item & $\begin{array}{c}\text { Mean assessment } \\
\text { score }\end{array}$ & $\begin{array}{c}\text { Mean discharge } \\
\text { Score }\end{array}$ & $\begin{array}{l}\text { Wilcoxon signed } \\
\text { ranks test } \\
\text { (two tailed) }\end{array}$ \\
\hline 1. Aggressive behaviour & 1.10 & .79 & $\mathrm{Z}=-2.59, \mathrm{p}=.010^{* *}$ \\
\hline 2. Self-injury & 1.06 & .53 & $\mathrm{Z}=-4.19, \mathrm{p}=.000 * *$ \\
\hline 3. Alcohol / drugs & .90 & .72 & $\mathrm{Z}=-2.06, \mathrm{p}=.040^{*}$ \\
\hline 4. Cognitive problems & .43 & .16 & $\mathrm{Z}=-3.31, \mathrm{p}=.001 * *$ \\
\hline 5. Physical illness & .44 & .32 & $\mathrm{Z}=-1.66, \mathrm{p}=.096$ \\
\hline 6. Hallucinations/delusions & .25 & .06 & $\mathrm{Z}=-2.07, \mathrm{p}=.038 *$ \\
\hline 7. Depressed mood & 1.81 & .99 & $\mathrm{Z}=-5.65, \mathrm{p}=.000 * *$ \\
\hline 8. Other mental problems & 1.21 & .67 & $\mathrm{Z}=-4.30, \mathrm{p}=.000 * *$ \\
\hline 9. Relationships & 1.35 & 1.07 & $\mathrm{Z}=-2.70, \mathrm{p}=.007 * *$ \\
\hline 10. Daily living activities & .75 & .57 & $\mathrm{Z}=-2.45, \mathrm{p}=.014 * *$ \\
\hline 11. Living conditions & .34 & .31 & $Z=-.95, p=.341$ \\
\hline 12. Occupation / activities & .37 & .24 & $\mathrm{Z}=-2.50, \mathrm{p}=.013^{* *}$ \\
\hline Total HoNOS score & 9.96 & 6.50 & $\mathrm{Z}=5.67, \mathrm{p}=0.000^{* *}$ \\
\hline
\end{tabular}

\footnotetext{
*: significant at $\mathrm{p}<0.05$

**: significant at $\mathrm{p}<0.01$
} 


\section{Comparison of pre- and post- intervention risk assessment scores}

No significant differences were identified between pre- and post-intervention risk assessment scores on any items, except for 'self-harm' which was found to decrease following mental health intervention $(Z=$ $-2.31, \mathrm{p}=0.021)$.

\section{Exploratory analysis into factors associated with changes in HoNOS scores}

Change in HoNOS scores was entered as the dependent variable in a series of Mann-
Whitney U Tests which incorporated demographic, history, risk and service dichotomous variables, as the grouping variable (Table III). The variables that differentiated the two groups, thus associated with significant reduction in HoNOS scores, were: previous experience of mental health problems prior to their current referral $(Z=-2.23, \mathrm{p}=$ $0.026)$; experience of drug abuse $(Z=-2.04$, $\mathrm{p}=0.041)$; planned last contact with their mental health worker $(Z=-3.34, \mathrm{p}=0.001)$; and practitioner's satisfaction with the number of sessions $(Z=-2.51, \mathrm{p}=0.012)$.

Spearman's rank correlation coefficients were conducted between four further variables and HoNOS change scores (Table IV). No significant associations were identified

Table III

Association between gender, history variables, risk factors at the time of assessment, and intervention variables with HoNOS change scores (pre-intervention total HoNOS score minus post intervention total HoNOS score).

\begin{tabular}{|c|c|c|c|c|c|c|}
\hline \multirow[b]{2}{*}{ Gender $(\mathrm{a}=$ male, $\mathrm{b}=$ female $)$} & \multirow[t]{2}{*}{$\mathrm{N}$} & \multirow{2}{*}{$\begin{array}{c}\begin{array}{c}\text { Mean change } \\
\text { score for sub } \\
\text { sample a }\end{array} \\
3.84(n=38)\end{array}$} & \multirow{2}{*}{$\begin{array}{c}\begin{array}{c}\text { Mean change } \\
\text { score for sub } \\
\text { sample b }\end{array} \\
2.97(\mathrm{n}=30)\end{array}$} & \multicolumn{3}{|c|}{$\begin{array}{c}\text { Mann-Whitney } \\
\text { U test } \\
\text { (two tailed) }\end{array}$} \\
\hline & & & & $\mathrm{U}=496.50$ & $Z=-.91$ & $\mathrm{p}=.361$ \\
\hline $\begin{array}{l}\text { Previously in care }(a=\text { yes, } b=\text { no }) \\
\text { Ever slept on the streets }\end{array}$ & 64 & $3.40(\mathrm{n}=10)$ & $3.63(\mathrm{n}=54)$ & $\mathrm{U}=259.50$ & $Z=-.20$ & $\mathrm{p}=.845$ \\
\hline$(a=$ yes, $b=$ no) & 63 & $2.07(\mathrm{n}=14)$ & $3.63(\mathrm{n}=49)$ & $\mathrm{U}=258.00$ & $Z=-1.41$, & $\mathrm{p}=.157$ \\
\hline Smoked $(\mathrm{a}=$ yes, $\mathrm{b}=$ no) & 6 & $3.83(\mathrm{n}=53)$ & $2.21(\mathrm{n}=14)$ & $\mathrm{U}=275.00$ & $\mathrm{Z}=-1.49$, & $\mathrm{p}=.137$ \\
\hline Taken drugs $(\mathrm{a}=$ yes, $\mathrm{b}=$ no $)$ & 66 & $3.71(n=51)$ & $2.60(n=15)$ & $\mathrm{U}=350.50$ & $Z=-.49$ & $\mathrm{p}=.623$ \\
\hline Overdosed $(a=$ yes, $b=$ no $)$ & 55 & $3.11(n=18)$ & $3.19(\mathrm{n}=37)$ & $\mathrm{U}=295.50$ & $Z=-.68$ & $\mathrm{p}=.498$ \\
\hline Self-harmed $(a=$ yes, $b=$ no $)$ & 66 & $3.62(\mathrm{n}=34)$ & $3.31(\mathrm{n}=32)$ & $\mathrm{U}=464.00$ & $Z=-1.03$, & $\mathrm{p}=.302$ \\
\hline Considered suicide $(\mathrm{a}=$ yes, $\mathrm{b}=\mathrm{no})$ & 67 & $3.85(\mathrm{n}=46)$ & $2.62(\mathrm{n}=21)$ & $\mathrm{U}=417.00$ & $Z=-.90$ & $\mathrm{p}=.370$ \\
\hline Attempted suicide $(a=$ yes, $b=$ no) & 65 & $2.75(\mathrm{n}=24)$ & $3.80(n=41)$ & $\mathrm{U}=436.50$ & $Z=-.76$ & $\mathrm{p}=.448$ \\
\hline Worked on the streets $(a=$ yes, $b=$ no $)$ & 64 & $.00(\mathrm{n}=1)$ & $3.51(\mathrm{n}=63)$ & $\mathrm{U}=9.00$ & $Z=-1.23$, & $\mathrm{p}=.313$ \\
\hline Been bullied $(\mathrm{a}=$ yes, $\mathrm{b}=$ no $)$ & 61 & $3.37(\mathrm{n}=35)$ & $3.58(\mathrm{n}=26)$ & $\mathrm{U}=429.00$ & $Z=-.38$ & $\mathrm{p}=.703$ \\
\hline $\begin{array}{l}\text { Been physically abused as a child } \\
\text { under the age of } 16(a=y e s, b=\text { no })\end{array}$ & 57 & $3.29(\mathrm{n}=21)$ & $3.22(\mathrm{n}=36)$ & $\mathrm{U}=363.00$ & $=-.25$ & $\mathrm{p}=.803$ \\
\hline $\begin{array}{l}\text { Been physically abused as an adult } \\
\text { over the age of } 16(a=y e s, b=\text { no })\end{array}$ & 57 & $3.21(n=14)$ & $3.26(n=43)$ & $\mathrm{U}=258.00$ & $Z=-.80$ & $\mathrm{p}=.422$ \\
\hline $\begin{array}{l}\text { Been sexually abused as a child } \\
\text { under the age of } 16(a=y e s, b=\text { no })\end{array}$ & 57 & $1.92(\mathrm{n}=13)$ & $3.61(n=44)$ & $\mathrm{U}=221.50$ & $Z=-1.24$, & $\mathrm{p}=.216$ \\
\hline $\begin{array}{l}\text { Been sexually abused or assaulted } \\
\text { as an adult over the age of } 16 \\
(\mathrm{a}=\text { yes, } \mathrm{b}=\text { no) }\end{array}$ & 58 & $1.38(\mathrm{n}=8)$ & $3.58(\mathrm{n}=50)$ & $\mathrm{U}=136.00$ & $Z=-1.45$, & $\mathrm{p}=.155$ \\
\hline
\end{tabular}




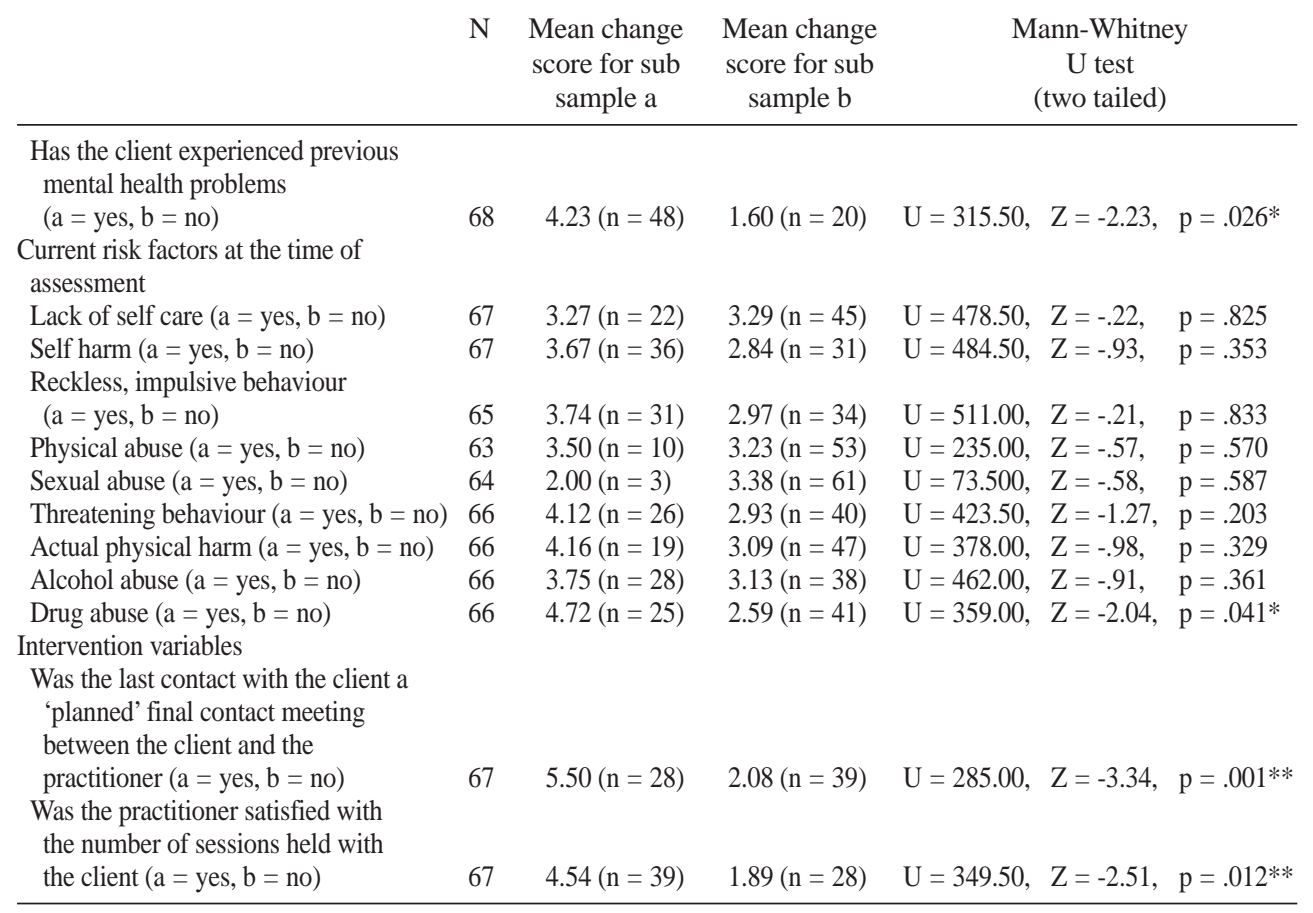

*: significant at $\mathrm{p}<0.05$

$* *$ : significant at $\mathrm{p}<0.01$

between HoNOS change scores and either the age of the young person at first contact with the service, the young person's level of mental health need at assessment, or the number of sessions held between young people and mental health professionals. A significant inverse correlation was however identified between HoNOS change scores and the number of times young people failed to attend sessions $\left(r_{s}=-0.45, p<0.001\right)$. The direction of the relationship between the two variables indicated that failing to attend more sessions was related with achieving lower levels of mental health improvement.

Table IV

Correlations between age, HoNOS score at initial assessment, service characteristics, and HoNOS change scores (pre-intervention total HoNOS score minus post-intervention total HoNOS score).

Mean N Spearman's rank correlation coefficient

Age at first contact

19.09

1.66

Level of mental health needs at assessment

$\mathrm{r}_{\mathrm{s}}=-.03, \mathrm{p}=.824$

How many times were sessions successfully held with the client

1.75

$\mathrm{r}_{\mathrm{s}}=.08, \mathrm{p}=.606$

How many times did the client fail to attend sessions

$\mathrm{r}_{\mathrm{s}}=.23, \mathrm{p}=.071$

*: significant at $\mathrm{p}<0.05$

**: significant at $\mathrm{p}<0.01$ 


\section{Discussion}

Young homeless people have a range of psychosocial needs, which can not easily be met by mental health services, unless coordinated with housing and social care agencies $^{6,10}$. In this study, we examined the short-term psychosocial outcome of young people who were in contact with a designated mental health service that provided input to 18 homeless shelters in five UK regions. Systematic data collection included a service checklist, a risk assessment and a clinical outcome measure (HoNOS) at the time of referral, and at completion of treatment or last contact with clinician. Despite the heterogeneity of the clinical sample (in diagnosis and social circumstances) and the interventions provided, a number of interesting conclusions can be drawn from the findings.

As previously established in a study by the research group ${ }^{10}$, the young homeless people presented with a range of mental health problems, longstanding histories of social adversity, and previous fragmented contacts with services. Despite the severity and complexity of their needs, young people were found to improve on the total HoNOS scores ratings, as well as on almost all HoNOS sub-scales. This is in accordance with previous studies that certain HoNOS sub-scales are more amenable to change following psychiatric interventions than others $^{22}$. The findings of this paper that subscales measuring aggression, non-accidental self-injury, cognitive problems, depressed mood, other mental and behavioural problems, relationships, activities of daily living, and occupation/activities, significantly decreased, are similar to the findings of Audin et $\mathrm{al}^{16}$.
Further exploration into variables that may have influenced change in pre- and post- HoNOS scores revealed that improvement in mental health was more likely for young people who had previously experienced mental health problems prior to their referral to the service, who were identified as being at risk of drug abuse at the point of referral, who did not miss many sessions, whose final contact with the service had been planned, and who attended a number of sessions deemed satisfactory by their mental health practitioner. Although young homeless people constitute a mobile group, often difficult to engage, and with rapidly changing life circumstances, there were positive messages from this study that, at least a substantial proportion appeared to engage in treatment and improve in several aspects of their functioning. Similar service models require more detailed evaluation, which was beyond the remit of this study. Also, more attention on the specific interventions provided for this group.

It has previously been identified that certain sub-scales within the HoNOS are more amenable to change following psychiatric interventions than others ${ }^{22}$. The findings of this paper that sub-scales 1 (overactive, aggressive, disruptive or agitated behaviour), 2 (non-accidental self-injury), 4 (cognitive problems), 7 (depressed mood), 8 (other mental and behavioural problems), 9 (relationships), 10 (activities of daily living), and 12 (occupation and activities) significantly decreased, are similar to the findings of Audin et al. ${ }^{16}$ of the highest changes within sub-scales 7, 8 and 9. This paper has also identified that the two most frequently reported problems specified under sub-scale 8 were $\mathrm{H}$ (sleep) followed by B (anxiety), which replicates the findings of Eager et al. ${ }^{20}$ of the same items being the most frequent in reverse order. 
The current study was limited by several factors. Although attempts were made to ensure that the mental health professionals received adequate training and supervision, the impact of the training was not formally assessed $^{23}$. Despite previous evidence that repeat ratings can be reliably conducted by the same mental health professional ${ }^{14}$, there is a possibility that the mental health professionals who were given the dual task of being responsible for both the delivery of clinical interventions and the collection of HoNOS data may have been biased by their own stake in the outcomes of the interventions they were offering. Previous studies have shown low reliability for certain HoNOS items, particularly 'living conditions' and 'problems with activities' 14 . Encouraging mental health professionals not to refer to their original ratings when conducting secondary ratings may have helped to reduce these potential biases. Finally, although this paper has identified statistically significant differences between pre- and post-intervention HoNOS total and sub-scale ratings, it has not been possible to identify whether these changes were clinically significant. Clinically significant change, where a patient's scores move from being dysfunctional to functional ${ }^{24}$, was not possible in the absence of independent diagnostic or other measures.

Despite the organizational difficulties of outreach work in hostels or other community settings, and patient turnover, it is important that data is collected in a systematic way, in order to accumulate evidence on young people's characteristics, service variables and, in particular, outcomes. Taking into consideration their complexity of needs and data completion by a range of practitioners from different disciplines, the HoNOS could be a useful tool in future service evaluation studies.

\section{Acknowledgments}

The research team wish to thank Tracy Jardine, Jane Keays, Anne-Marie Lyons, Lisa Shaw and Hayley Slater for their help with data collection on this project; Pat McAllister and Helen Old at the Foyer Federation for their support; and John Bankart at the Trent Research and Development Services Unit for statistical advice. This study was funded by the Gatsby Foundation.

\section{References}

1. Ensign J, Gittelsohn J. Health and access to care: perspectives of homeless youth in Baltimore City, USA. Soc Sci Medicine 1998; 47: 2087-2099.

2. Lindsey E, Kurtz D, Jarvis S, Nancy R, Nackerud L. How runaway and homeless youth navigate troubled waters: personal strengths and resources. Child Adolesc Soc Work J 2000; 17: 115-1140.

3. Commander M, Davis A, McCabe A. A comparison of homeless and domiciled young people. J M Health 2002; 11: 557-564.

4. Craig T, Hodson S. Homeless youth in London: I. Childhood antecedents and psychiatric disorder. Psychol Med 1998; 28: 1379-1388.

5. Tyler K, Cauce A. Perpetrators of early physical and sexual abuse among homeless and runaway adolescents. Child Ab Neglect 2002; 26: 1261-1274.

6. Craig T, Hodson S. Homeless youth in London: II. Accommodation, employment and health outcomes at one year. Psychol Med 2000; 30: 187-194.

7. Deckel R, Peled E, Spiro S. Shelters for houseless youth: a follow-up evaluation. J Adolescence 2003; 26: 201-212.

8. Pollio D, Thompson S, North C. Agency-based tracking of difficult-to-follow populations: runaway and homeless youth programs in St. Louis, Missouri. Comm M Health J 2000; 36: 247-258.

9. Susser E, Valencia E, Conover S, et al. Preventing recurrent homelessness among mentally ill men: a 'critical time' intervention after discharge from a shelter. Am J Public Health 1997; 87: 256-262. 
10. Taylor H, Stuttaford M, Broad B, Vostanis P. Why a 'roof' is not enough: the characteristics of young homeless people referred to a designated mental health service. J M Health 2006; 15: 491-501.

11. Taylor H, Stuttaford M, Vostanis P. A UK survey into how homeless shelters respond to the mental health needs of homeless young people. Housing, Care and Support 2006; 9: 13-18.

12. Wing J, Curtis R, Beevor A. HoNOS: Health of the Nation Outcome Scales: Report on Research and Development. London: College Research Unit; 1996.

13. Wing JK, Beevor AS, Curtis RH, Park S, Hadden S, Burns A. Health of the Nation Outcome Scales (HoNOS): Research and Development. Br J Psychiatry 1998; 172: 1118.

14. Wing JK, Lelliot P, Beevor AS. Progress on HoNOS. Br J Psychiatry 2000; 176: 392-393.

15. Allan S, McGonagle I A comparison of HoNOS with the Social Behavioural Schedule in three settings. J Mental Health 1997; 6: 117-124.

16. Audin K, Marginson FR, Clark JM, Barkham M. Value of HoNOS in assessing patient change in NHS psychotherapy and psychological treatment services. Br J Psychiatry 2001; 178: 561-566.

17. Stein G. Usefulness of the Health of the Nation Outcome Scales. Br J Psychiatry 1999; 174: 375-377.

18. D'Avanzo B, Battino R, Gallus S, Barbato A. Factors predicting discharge of patients from community resi- dential facilities: a longitudinal study from Italy. Aust New Zeal J Psychiatry 2004; 38: 619-628.

19. Gallagher J, Teeson M. Measuring disability, need and outcome in Australian community mental health services. Aust New Zeal J Psychiatry 2000; 34: 850-855.

20. Eager K, Trauer T, Mellsop G. Performance of routine outcome measures in adult mental health care. Austr New Zeal J Psychiatry 2005; 39: 713-718.

21. Salvi G, Leese M, Slade M. Routine use of mental health outcome assessments: choosing the measure. Br J Psychiatry 2005; 186: 146-152.

22. Trauer T, Callaly T, Hantz P. The measurement of improvement during hospitalisation for acute psychotic illness. Austr New Zealand J Psychiatry 1999; 33: 379-384.

23. Brooks R. The reliability and validity of the Health of the Nation Outcome Scales: validation in relation to patient derived measures. Austr New Zeal J Psychiatry 2000; 34: 504-511.

24. Parabiaghi A, Barbato A, D’Avanzo B, et al. Assessing reliable and clinically significant change of the Health of the Nation Outcome Scales: method for displaying longitudinal data. Austr New Zeal J Psychiatry 2005; 39: 719725.

Address for correspondence:

Helen Taylor

University of Leicester, Greenwood Institute of Child Health. Westcotes House, Westcotes Drive, Leicester LE3 0QU, UK

Tel: 0044116 2252885; Fax: 00441162252881 ;

E-mail: pv11@le.ac.uk 